\title{
Constructive features of the bank protection structure of water recreation facility in Arkhangelsk
}

\author{
Anna Kopteva ${ }^{1, *}$ and Alexey Lukin ${ }^{1}$ \\ ${ }^{1}$ Northern (Arctic) Federal University 163000, Arkhangelsk, nab. Severnaya Dvina, 17
}

\begin{abstract}
The objective of the study is projecting and calculation of shore protection structure of the water recreation facility in northern climatic conditions of Arkhangelsk city. In the course of study, three constructive solutions including anchored or non-anchored Larsen dowel wall were projected based on geotechnical conditions of Arkhangelsk. Geotechnical conditions include physico-mechanical and strength characteristics of soils, determined in accordance with the geological regulations. The calculation of bank protection structures was performed in PLAXIS 3D Foundation package by the finite element method. The study represents diagrams and graphics showing the deformations of bank protection structure. The result of the study is a solution chosen according to the reliability criterion. Recommendations and directions for the future research were proposed.
\end{abstract}

\section{Introduction}

Organized water recreation is a promising area of urban infrastructure in Arkhangelsk city. Objects of organized water recreation include yacht clubs, moorings, slipways etc.

Arkhangelsk is located in the mouth of the Northern Dvina at a distance of $30 \mathrm{~km}$ from the White Sea. Arkhangelsk refers to the Arctic zone of Russia; therefore, there are some challenges such as adverse engineering and geological conditions and rigorous climate. While projecting the objects of organized water recreation much attention should be given to the structural features of the berthing facilities.

In Archangelsk the ground is formed by plastic and turgid moraine loams lying at a depth of 2-2.5 $\mathrm{m}$ from the surface. During the periods of spring snowmelt and heavy rains the groundwater level lies near the surface. In the basin of the Northern Dvina, erosion is very strong. Therefore, the berthing facility should serve to strengthen the river bank.

Previously the issue of projecting berthing facilities in northern climatic conditions was considered in articles [1, 2]. Studies also showed that construction of objects of organized water recreation is the main condition for development of water infrastructure generally [3]. Besides, the development of water recreation will entail the development of tourism and attraction of investments, which will allow to build new facilities.

The objective of the current study is projecting and calculation of bank protection structure of the water recreation facility in northern climatic conditions of Arkhangelsk city.

* Corresponding author: annkopteva@mail.ru 


\section{Materials and methods}

Based on the results of geological surveys in the coastal zone of Arkhangelsk, the following stratification of soils has been identified:

- Soil №1 - technogenic soil - gray dusty water-saturated sand, layer thickness is $3 \mathrm{~m}$;

- Soil №2 - alluvial-marine sediments - fluid clayey mud, layer thickness is $7 \mathrm{~m}$;

- Soil №3 - diluvium - tough loam with 5\% amount of gravel and pebbles, layer thickness is $10 \mathrm{~m}$;

- Soil №4 - marine sediments - sand of medium density.

Physico-mechanical and strength characteristics of soils were determined in accordance with the GOST 12248-2010 [4] and GOST 20276-2012 [5]. The characteristics are presented in tables 1,2 .

Table 1. Physico-mechanical characteristics of soils

\begin{tabular}{|c|c|c|c|c|c|c|c|c|c|}
\hline \multirow{4}{*}{ 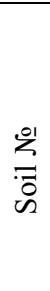 } & \multirow{4}{*}{$\overline{\bar{\delta}}$} & \multirow{4}{*}{ 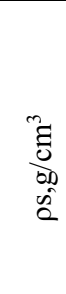 } & \multirow{2}{*}{\multicolumn{3}{|c|}{$\begin{array}{l}\text { Density } \rho, \\
\mathrm{g} / \mathrm{cm}^{3}\end{array}$}} & \multirow{4}{*}{ 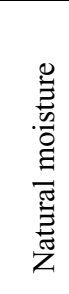 } & \multirow{4}{*}{ 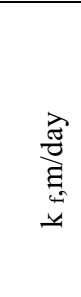 } & \multicolumn{2}{|c|}{ Cohesion, $\mathrm{kPa}$} \\
\hline & & & & & & & & \multirow{3}{*}{$\begin{array}{l}2 \\
0 \\
0 \\
\| \\
0 \\
0 \\
0\end{array}$} & \multirow{3}{*}{$\begin{array}{l}n \\
0 \\
0 \\
\| \\
0 \\
0 \\
0\end{array}$} \\
\hline & & & \multirow{2}{*}{$\begin{array}{l}\text { 离 } \\
\text { 泀 } \\
\text { Z }\end{array}$} & \multicolumn{2}{|c|}{$\alpha$} & & & & \\
\hline & & & & 0,95 & 0,85 & & & & \\
\hline 2 & $\begin{array}{l}\text { Fluid clayey } \\
\text { mud am }\end{array}$ & 2,21 & 1,62 & 1,52 & 1,57 & 0,62 & 0,031 & 10,62 & 11,9 \\
\hline 3 & $\begin{array}{c}\text { Tough loam } \\
\text { with } 5 \% \\
\text { amount of } \\
\text { gravel and } \\
\text { pebbles gIII }\end{array}$ & 2,73 & 2,15 & 2,10 & 2,10 & 0,18 & 0,033 & 42,38 & 44,3 \\
\hline 4 & $\begin{array}{l}\text { Medium- } \\
\text { density sand } \\
\text { mIII }\end{array}$ & 2,65 & 2,07 & 1,98 & 2,03 & 0,21 & 0,800 & 1,75 & 3,60 \\
\hline
\end{tabular}

Table 2. Strength characteristics of soils

\begin{tabular}{|c|c|c|c|c|c|c|c|c|c|}
\hline \multirow{2}{*}{$\begin{array}{c}\text { Soil } \\
\text { № }\end{array}$} & \multicolumn{2}{|c|}{$\begin{array}{l}\text { Angle of internal } \\
\text { friction }\end{array}$} & \multirow{2}{*}{$\begin{array}{l}\mathrm{E}, \\
\mathrm{MPa}\end{array}$} & \multirow{2}{*}{$\mathrm{e}$} & \multirow{2}{*}{$\begin{array}{l}\rho d \\
\mathrm{~g} / \mathrm{cm}^{3}\end{array}$} & \multirow{2}{*}{$\begin{array}{c}\gamma, \\
\mathrm{kN} / \mathrm{m}^{3}\end{array}$} & \multirow{2}{*}{$\mathrm{Sr}$} & \multirow{2}{*}{ Ip } & \multirow{2}{*}{$\mathrm{I}_{\mathrm{L}}$} \\
\hline & $\begin{array}{c}\varphi \mathrm{I} \\
\alpha=0,95\end{array}$ & $\begin{array}{c}\varphi \mathrm{II} \\
\alpha=0,85\end{array}$ & & & & & & & \\
\hline 2 & 8,52 & 9,70 & 7,60 & 1,21 & 1 & 15,89 & 1,13 & 0,25 & 1,08 \\
\hline 3 & 13,65 & 15,10 & 15,58 & 0,50 & 1,82 & 21,09 & 0,99 & 0,09 & 0,33 \\
\hline 4 & 34,74 & 35,80 & 11,31 & 0,55 & 1,71 & 20,31 & 1,01 & & \\
\hline
\end{tabular}

The calculation is performed in PLAXIS 3D Foundation by the finite element method. The finite element method (FEM) is the main method of modern construction mechanics, which is the basis of most modern software complexes designed to perform calculations of building structures on a computer. 
The finite element method is based on the representation of a real construction by its discrete model. Differential equations describing the stress-strain states of continuous bodies are replaced by a system of algebraic equations. The essence of that method is that the area occupied by the construction is divided into a number of small subdomains, which size is finite [6]. Subdomains are called finite elements (FE), and the process of breaking down is called discretization.

PLAXIS 3D Foundation is a finite element package that has been developed specifically for the analysis of deformation, stability and flow in geotechnical engineering projects. The simple graphical input procedures enable a quick generation of complex finite element models, and the enhanced output facilities provide a detailed presentation of computational results. The calculations are fully automated and based on robust numerical procedures [7].

The following constructive solutions of shore reinforcement structures for geotechnical conditions of Arkhangelsk were suggested. All variants are based on Larsen dowel L-4 [8], length of 15 meters.

The first constructive solution is the non-anchored dowel wall.

The second constructive solution includes anchored dowel wall and bored piles made of reinforced concrete. Piles have square cross-section measuring $300 * 300$ millimeters length of 10 meters. Anchor rods are a steel rope with a diameter of 49 millimeters.

The third constructive solution includes anchored dowel wall and a support concrete wall length of 1,5 meters, 300 millimeters thick. Two walls are connected with steel anchor rods. Fluid clayey mud is extracted and the vacated space is filled with sand.

№ 1

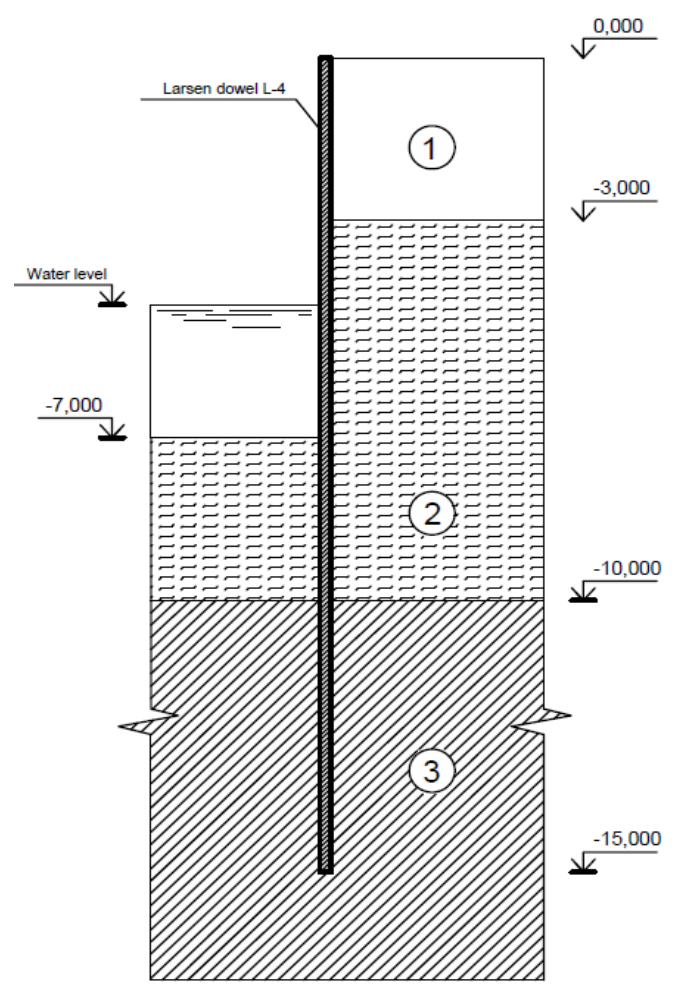

Fig. 1. Constructive solution №1. 
№ 2

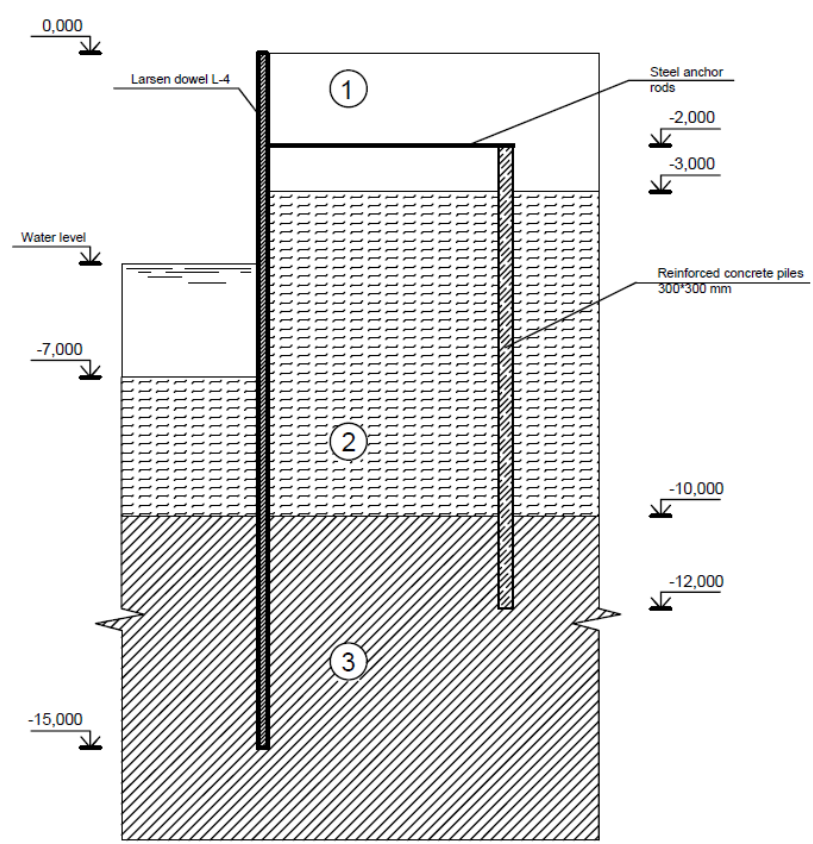

Fig. 2. Constructive solution №2.

№ 3

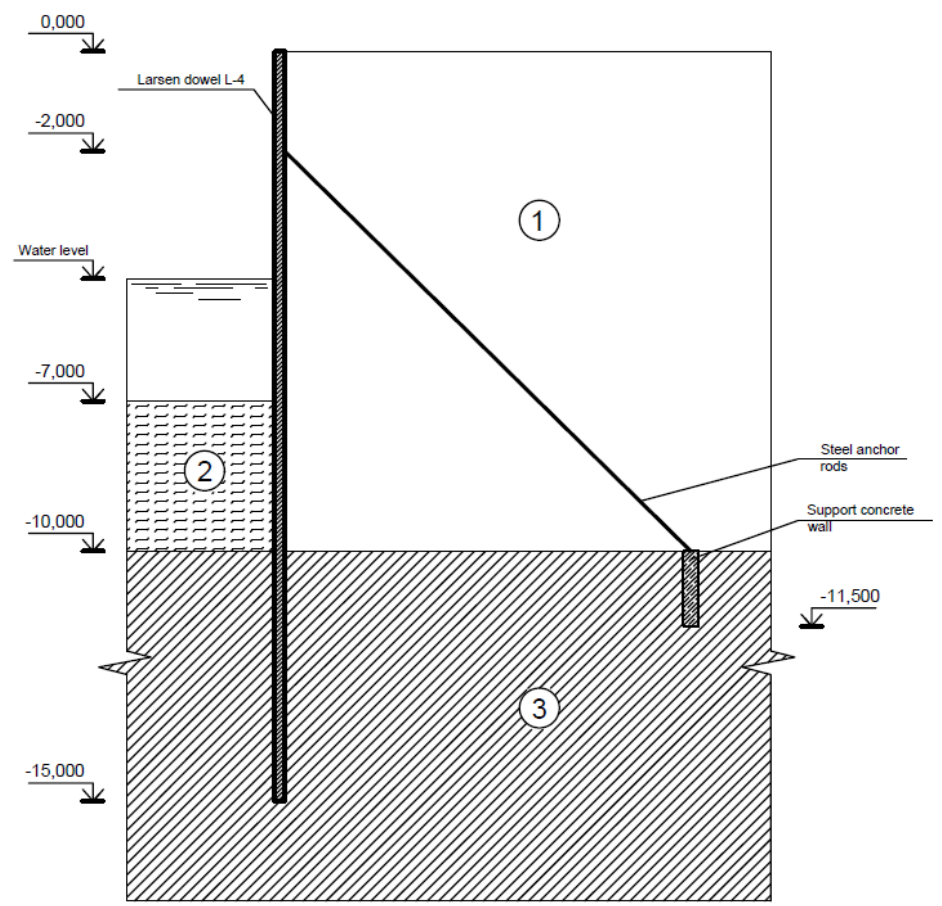

Fig. 3. Constructive solution №3. 


\section{Results}

Calculation of the first constructive solution of shore protection structure begins with modeling of the identified geological conditions.

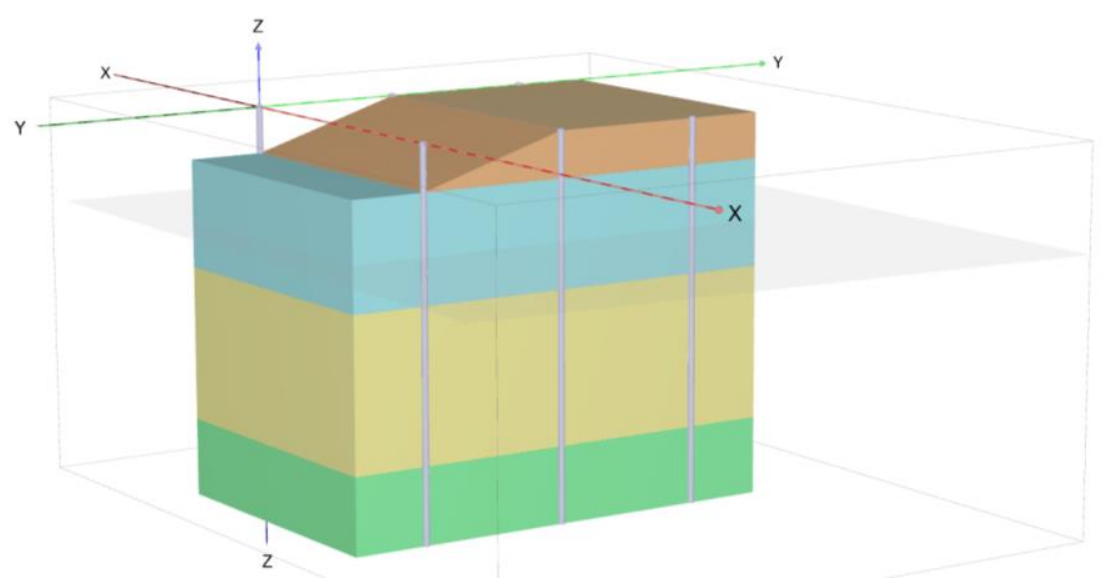

Fig. 4. Modeling of geological conditions.

Next step is modeling of the construction. Then the program creates a finite element grid and checks the safety factor.

\begin{tabular}{|c|c|c|}
\hline Nar & & Value \\
\hline \multicolumn{3}{|c|}{$\exists$ General } \\
\hline & ID & Phase_2 \\
\hline & Start from phase & Phase_1 \\
\hline & Calculation type & $\sqrt{ }$ Safety \\
\hline & Loading type & $\Delta$ Incremental multiplier $>$ \\
\hline & $M_{s f}$ & 0,1000 \\
\hline & Pore pressure calculation type & $\downarrow$ Use pressures from $\mathrm{F}$. \\
\hline & First step & 46 \\
\hline & Last step & 145 \\
\hline
\end{tabular}

Fig. 5. Safety factor check.

The value of total displacements of construction is $0,137 \mathrm{~m}$. Such a value of displacements is unacceptable. 


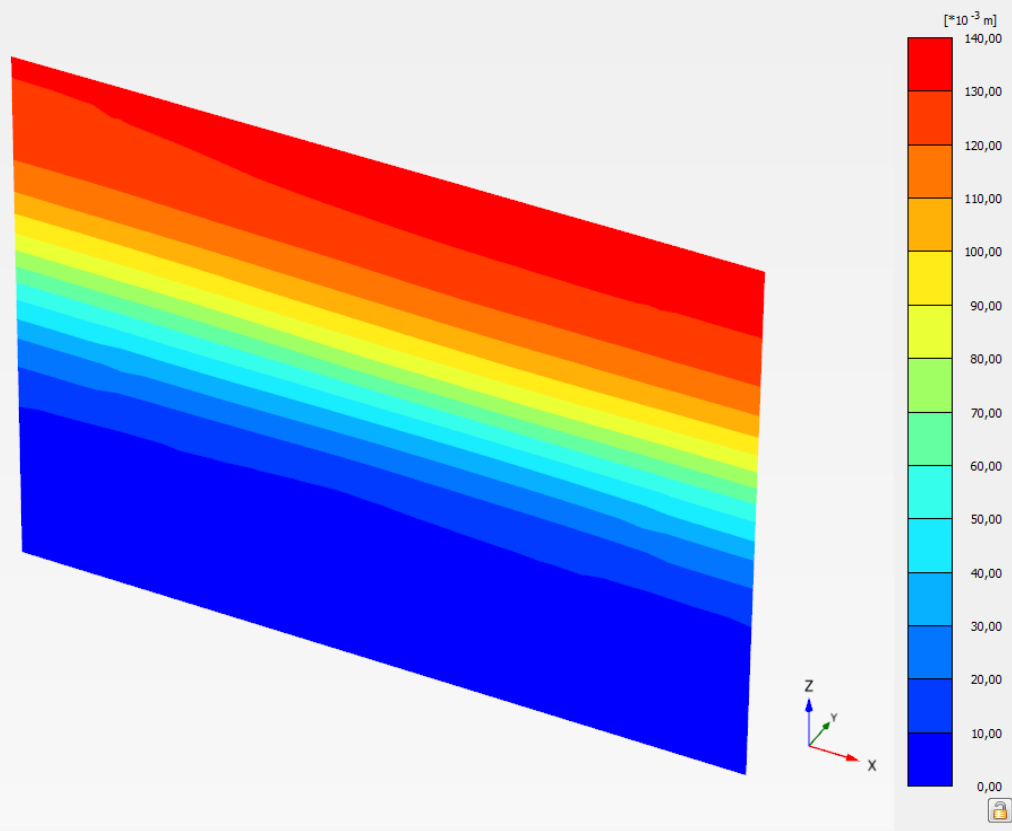

Fig. 6. Total displacements of the first constructive solution.

Calculation of the second constructive solution is perfomed in the same sequence. The value of total displacements of construction is $0,075 \mathrm{~m}$.

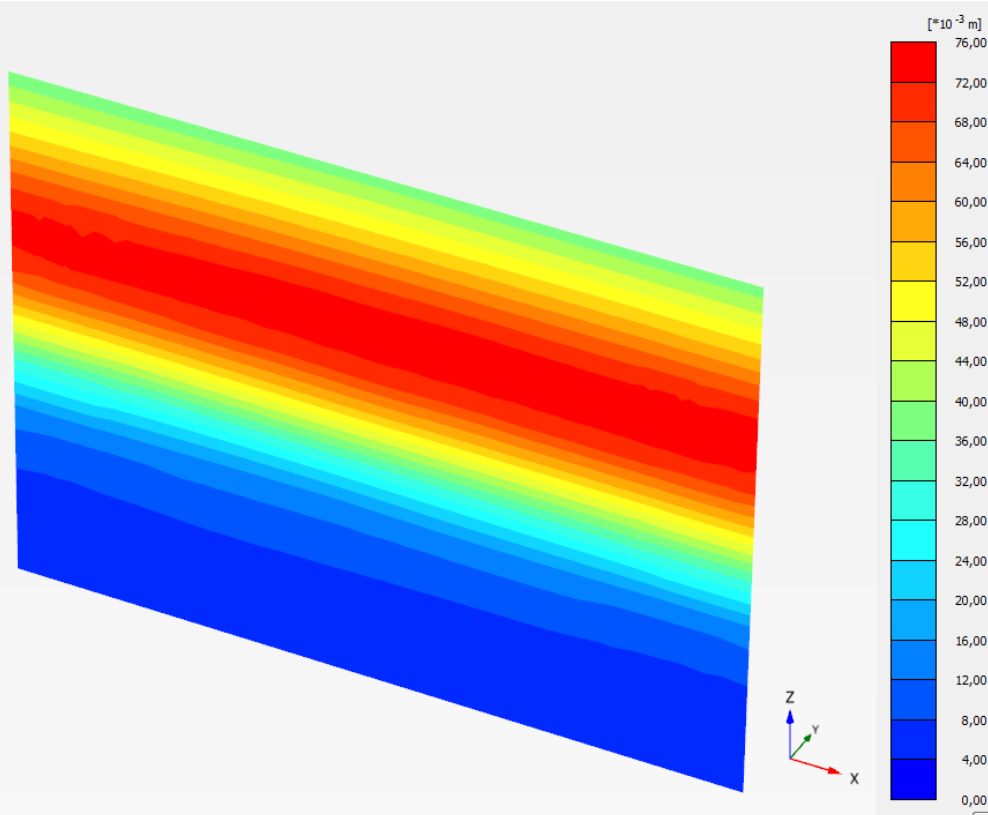

Total displacements $|u|$

Maximum value $=0,07509 \mathrm{~m}$ (Element 191 at Node 3099)

Fig. 7. Total displacements of the second constructive solution. 
Section of the calculation model is shown on the figure below. It shows the distribution of soil deformation.

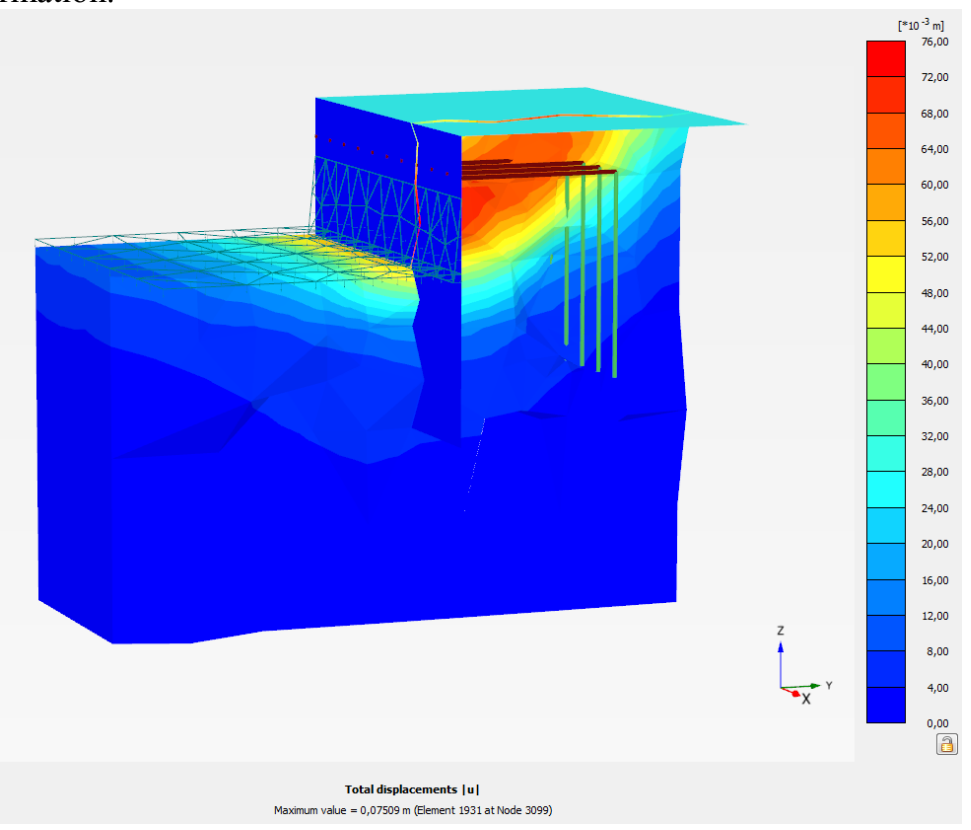

Fig. 8. The model of the second constructive solution.

Safety factor $\Sigma \mathrm{Msf}=2,147>1$.

The second constructive solution of shore reinforcement structure is recommended for further construction.

\begin{tabular}{|c|c|c|c|c|c|}
\hline \multirow[t]{9}{*}{$\boxminus$} & \multicolumn{5}{|l|}{ Step info } \\
\hline & Phase & Phase_3 [Phase_3] & & & \\
\hline & Step & Initial & & & \\
\hline & Step type & Safety & & & \\
\hline & Updated mesh & False & & & \\
\hline & Solver type & Picos & & & \\
\hline & Kernel type & 64 bit & & & \\
\hline & Extrapolation factor & 1,000 & & & \\
\hline & Relative stiffness & $0,2239 \mathrm{E}-3$ & & & \\
\hline \multicolumn{6}{|c|}{$\boxminus$ Multipliers } \\
\hline & Soil weight & & & $\Sigma M_{\text {Weight }}$ & 1,000 \\
\hline & Strength reduction factor & $M_{s f}$ & $5,475 E-3$ & $\sum M_{s f}$ & 2,147 \\
\hline & Time & Increment & 0,000 & End time & 0,000 \\
\hline
\end{tabular}

Fig. 10. Calculation of safety factor.

The value of total displacements of the third constructive solution is $0,01 \mathrm{~m}$ : 


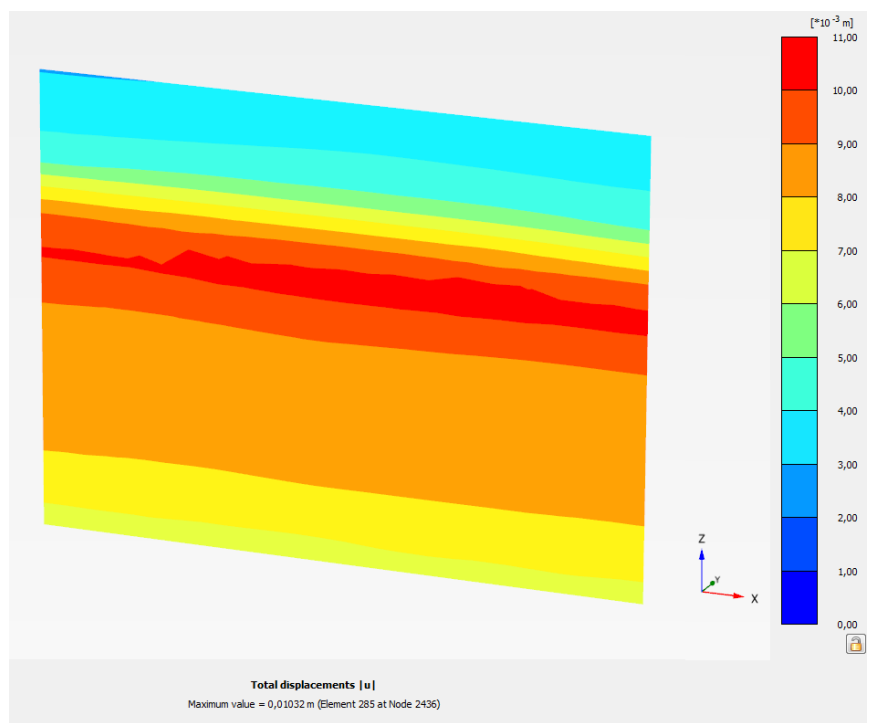

Fig. 11. Total displacements of the third constructive solution.

Section of the calculation model is shown on the figure below.

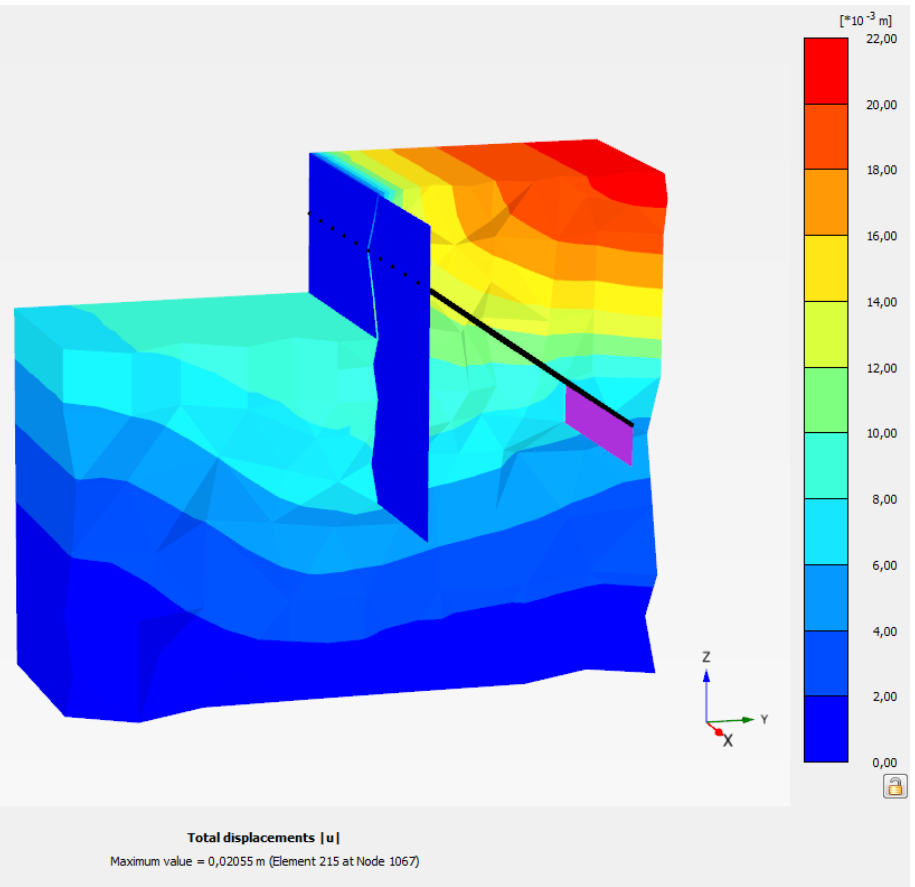

Fig. 12. The model of the third constructive solution.

Safety factor $\Sigma \mathrm{Msf}=2,664>1$.

The third constructive solution of shore reinforcement structure is recommended for further construction. 


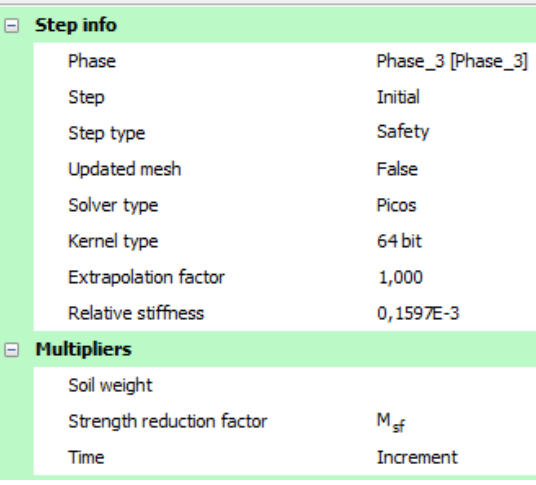

Fig. 13. Calculation of safety factor.

\section{Discussion}

Based on the results of calculations above, it is recommended to use the second and the third constructive solutions for further construction. These two variants are shown in the Table 3.

Table 3. Comparison of two suitable constructive solutions.

\begin{tabular}{|c|c|c|}
\hline & $2^{\text {nd }}$ constructive solution & 3rd constructive solution \\
\hline \multicolumn{3}{|l|}{ Model } \\
\hline $\begin{array}{c}\text { Total } \\
\text { displacements, } \\
\mathrm{m}\end{array}$ & 0,075 & 0,01 \\
\hline $\begin{array}{l}\text { Main item for } \\
\text { construction } \\
\text { costs }\end{array}$ & Palification & Backfilling with sand \\
\hline
\end{tabular}

The main criterion of comparison is the reliability. It is recommended to accept the third variant of the construction since this option is the most reliable.

Both options involve large expenditure items, therefore it is recommended to conduct an economic calculation of both constructive solutions, including the costs of work and materials. Based on the future economic calculation, a more economical constructive solution can be used.

The obtained result represents the great importance for the construction of water recreation facilities in the Arctic zone. Engineered options can be widely used in practice both in Arkhangelsk region and in other regions with similar geotechnical conditions. 


\section{Conclusion}

The current study showed the following results. Three constructive solutions of shore reinforcement structures for geotechnical conditions of Arkhangelsk based on Larsen dowel were suggested. The calculation of the proposed structures was perfomed in the Plaxis 3D Foundation package. Based on this calculation, the most reliable option was chosen.

On the basis of the proposed constructive solution it is recommended to develop a technological map with a choice of machines and mechanisms for the successful implementation of the project.

\section{References}

1. M. Busin, A. Varfolomeev, Y. Markov, A. Popov, Influence of high water on the state of buildings in Arkhangelsk (2011)

2. A. Kopteva, Constructive features of yacht club's constructions in climatic and geological conditions of Archangelsk (2017)

3. S. Zvyagin, Buziness Class, Passing wind in the sails of tourism, (2016)

4. Russian Standard GOST 12248-2010, Soils. Laboratory methods for determining the strength and strain characteristics (2010)

5. Russian Standard GOST 20276-2012, Soils. Field methods for determining the strength and strain characteristics (2012)

6. V.Bazhenov, A. Perelmuter, O.Shishov, Construction mechanics. Computer technologies and modeling (2014)

7. Plaxis 3D Foundation Tutorial Manual (2016)

8. A. Tsernant, N. Efremov, V. Goncharov, Scientific support of development of designs of implementation of transport facilities made of welded dowel (Build. mater., equip., technolog. of the XXI cent., 2011) 